\title{
Resveratrol affects the lipid profile but not antioxidant enzymes gene expression in rats fed hypercholesterolaemic diet
}

\author{
A. Kopeć ${ }^{1}$, E. Piątkowska and T. Leszczyńska \\ Agricultural University of Krakow, Department of Human Nutrition, \\ Balicka 122, 30-149 Kraków, Poland
}

KEY WORDS: resveratrol, high-fat diet, lipid profile, antioxidant enzymes, gene expression, rats

Received: 6 November 2012

Revised: 27 February 2013

Accepted: 17 June 2013

${ }^{1}$ Corresponding author: e-mail: akopec@ar.krakow.pl

\begin{abstract}
The objective of this study was to evaluate the effect of adding resveratrol (RSV) to a hypercholesterolaemic diet on the lipid profile, activity of antioxidant enzymes and their mRNA gene expression, as well as lipid concentration in selected organs of Wistar rats. Animals were divided into four groups and fed experimental diets for 8 weeks. The negative control group (NC) was fed AIN-93G diet. The positive control group (PC) received a hypercholesterolaemic diet (AIN-93G + 0.1\% cholesterol, $7 \%$ butter). The other groups were fed PC diets supplemented with $0.05 \%$ and $0.1 \%$ RSV, respectively. An addition to the PC diet RSV ( 0.05 and $0.1 \%$, respectively) significantly decreased concentration of total cholesterol (TC) and LDL-cholesterol in serum of rats compared to the PC group. The triacylglycerols (TAG) level was significantly lower in serum of rats fed with $0.05 \%$ of RSV in comparison to other experimental groups. Activities of antioxidant enzymes and their mRNA gene expression were not affected by RSV. In conclusion, relatively high doses of RSV were sufficient in lowering TC and LDL-cholesterol, and TAG and oxidative stress without involving naturally occurring mechanisms in rats.
\end{abstract}

\section{Introduction}

Resveratrol (3,4',5-trihydroksystilbene) (RSV) belongs to non-nutrient bioactive compounds. Its healthy properties are connected with antioxidant, anti-inflammatory and anti-aging properties. In several studies it was reported that RSV decreases oxidative stress in various animal models and may be used in the prevention and treatment of non-communicable diseases, e.g. dyslipidaemia, obesity, hypertension and diabetes (Lagouge et al., 2006; Leiro et al., 2010; Kim et al., 2011).

An unbalanced diet, especially a high intake of saturated fatty acids and cholesterol, is a risk factor for many diseases: hypertension, obesity and cardiovascular diseases (Kaput, 2004; Cho et al., 2012). It is causes by an increased level of LDL-cholesterol
(Artaud-Wild et al., 1993, Yamagishi et al., 2013). Additionally it has been also well reported that cholesterol in the presence of animal origin fat (butter or lard) added to the experimental diets increases total cholesterol (TC), LDL-cholesterol and oxidative stress (mainly by oxidative modification of LDL 1ipoproteins) in animal models (Yuan et al., 1998; Pisulewski et al., 2002; Yuan and Kitts, 2003; Rocha et al., 2009; Zawistowski et al., 2009).

Reactive oxygen species (ROS) in the body can cause lipid and protein oxidation, DNA damage, modification and modulation of gene expression. Imbalance between ROS and antioxidants causes oxidative stress (Kim et al., 2011; Kitada et al., 2011). In the human body several mechanisms are involved in the scavenging of ROS for example antioxidant enzymes such as: glutathione reductase (GSR), super- 
oxide dismutase (SOD), haeme oxygenase 1 (HO-1). The human body usually requires more substances which will neutralize ROS. Naturally occurring in daily diets, antioxidants and other chemical bioactive compounds help detoxify ROS and prevent the damaging of cellular macromolecules and organelles through several metabolic pathways. Several studies with different animal models reported that the addition of RSV in dose-depended manner to various experimental diets (with high-fat content, e.g. 52\% soya bean oil, $42 \%$ lipids or $60 \%$ energy from fat; or addition of fructose to diets in high amount, e.g. $63 \%$ ) increases the production of antioxidant enzymes in tissues and decreases the content of ROS (Aubin et al., 2008; Rocha et al., 2009; Kitada et al., 2011; Tauriainen et al., 2011; Kopeć et al., 2013).

In this research it was hypothesized that the addition of cholesterol and butter to the experimental diets increase lipid profile and oxidative stress, but the addition of resveratrol decreases them, without involving naturally occurring mechanisms.

The objective of this study was to evaluate the effect of the addition of RSV to the hypercholesterolaemic diet on lipid profile, the activity of antioxidant enzymes and their mRNA gene expression, as well as lipid concentration in selected organs of Wistar rats.

\section{Material and methods}

\section{Animal study}

Five weeks-old male Wistar rats $(n=24)$, were purchased from Animal Husbandry in Warsaw (Poland). All experimental procedures were approved by I Regional Ethics Committee on Animal Experimentation in Krakow (Poland). Before the experiment animals were acclimatized for 7 days on standard laboratory diet. At the beginning of the experiment the average body mass of animals was $116 \pm 10 \mathrm{~g}$. After the adaptation period rats were randomly divided into four groups $(n=6)$ and fed with diets prepared based on AIN-93G (Reveers, 1997). The composition of experimental diets is shown in Table 1. The animals were housed separately in stainless steel metabolic cages at $25^{\circ} \mathrm{C}$ and $12 / 12 \mathrm{~h}-$ light/dark cycle. During the experiment, animals had free access to water and diets. Intakes of diets were recorded every day. Body weight gain was recorded during the whole experiment every week.

At the end of the experiment (after 8 weeks), fasted rats were anaesthetized with thiopental (Biocheme $\mathrm{GmbH}$, Austria). Blood was obtained by heart puncture. Parts of blood samples were collected in heparinized tubes. Other parts of blood
Table 1. Composition of experimental diets, $\mathrm{g} \cdot \mathrm{kg}^{-1}$ diet

\begin{tabular}{|c|c|c|c|c|}
\hline Ingredient & NC & PC & $\begin{array}{l}\text { PC } \\
+ \text { RSV } 0.05 \%\end{array}$ & $\begin{array}{l}\text { PC } \\
+ \text { RSV } 0.1 \%\end{array}$ \\
\hline Maize starch & 532.486 & 522.486 & 521.986 & 521.486 \\
\hline Caseine & 200 & 200 & 200 & 200 \\
\hline Saccharose & 100 & 100 & 100 & 100 \\
\hline Soya bean oil & 70 & - & - & - \\
\hline Butter & - & 70 & 70 & 70 \\
\hline Fibre & 50 & 50 & 50 & 50 \\
\hline Mineral mix ${ }^{1}$ & 35 & 35 & 35 & 35 \\
\hline Vitamin mix ${ }^{1}$ & 10 & 10 & 10 & 10 \\
\hline Choline & 2.5 & 2.5 & 2.5 & 2.5 \\
\hline $\mathrm{TBHQ}^{2}$ & 0.014 & 0.014 & 0.014 & 0.014 \\
\hline Cholesterol & - & 10 & 10 & 10 \\
\hline Resveratrol & - & - & 0.5 & 1 \\
\hline Gross energy, $\mathrm{k}$ & 3960 & 3920 & 3918 & 3916 \\
\hline \multicolumn{5}{|c|}{ Fatty acids composition, \% } \\
\hline $4: 0$ & - & 3.25 & 3.10 & 3.10 \\
\hline $6: 0$ & - & 2.29 & 2.25 & 2.21 \\
\hline $8: 0$ & - & 1.40 & 1.40 & 1.34 \\
\hline $10: 0$ & 0.056 & 3.14 & 3.13 & 3.41 \\
\hline $12: 0$ & 0.067 & 3.44 & 3.43 & 3.50 \\
\hline $14: 0$ & 0.227 & 11.35 & 11.38 & 11.85 \\
\hline $14: 1$ & 0.011 & 1.01 & 1.00 & 1.04 \\
\hline 15:0 & 0.030 & 1.00 & 1.01 & 1.06 \\
\hline $16: 0$ & 10.12 & 34.30 & 34.20 & 34.59 \\
\hline $16: 1(n-9)$ & 0.022 & 0.10 & 0.11 & 0.10 \\
\hline $16: 1(n-7)$ & 0.087 & 1.56 & 1.60 & 1.61 \\
\hline $17: 0$ & 0.073 & 0.46 & 0.48 & 0.47 \\
\hline $17: 1$ & 0.039 & 0.23 & 0.21 & 0.21 \\
\hline $18: 0$ & 3.96 & 9.01 & 9.07 & 9.20 \\
\hline $18: 1(n-9)$ & 23.15 & 21.56 & 21.61 & 21.58 \\
\hline $18: 1(n-7)$ & 2.25 & 1.96 & 2.00 & 1.92 \\
\hline $18: 2(n-6)$ & 53.90 & 2.54 & 2.51 & 2.41 \\
\hline $18: 3(n-6)$ & - & 0.07 & 0.07 & 0.07 \\
\hline $18: 3(n-3)$ & 5.61 & 0.43 & 0.38 & 0.38 \\
\hline $20: 0$ & 0.27 & 0.096 & 0.10 & 0.10 \\
\hline $20: 1$ & 0.14 & 0.07 & 0.07 & 0.07 \\
\hline
\end{tabular}

NC-AIN-93G diet; PC - hypercholesterolaemic diet; PC+0.05\% RSV -- hypercholesterolaemic diet with addition of $0.05 \%$ RSV; $\mathrm{PC}+0.1 \%$ RSV - hypercholesterolaemic diet with addition of $0.1 \%$ RSV, ${ }^{1}$ AIN-93G; TBHQ ${ }^{2}$ - tert-butylohydroquinone

samples were collected to obtain serum by centrifugation (1500 g, $15 \mathrm{~min})$. Livers, kidneys and hearts were dissected, washed in $0.9 \%$ sodium chloride, dried with laboratory tissue paper and weighed. Serum and tissue samples were kept frozen in $-80^{\circ} \mathrm{C}$ until the analysis.

\section{Composition of fatty acids in experimental diets}

The composition of fatty acids of the experimental diets was analysed by gas chromatography after the extraction of lipids from the experimental diets using the Folch's method (Folch et al., 1957). Fatty acids were esterified with $0.0025 \mathrm{M}$ sodium 
methoxide (de Man, 1964) and separated with the Trace GC Ultra model (Thermo Scientific Electron Corporation, USA), using a capillary Supelcowax 10 column $(30 \mathrm{~m} \times 0.25 \mathrm{~mm} \times 0.25 \mu \mathrm{m}$; Supelco, Bellefonte, PA, USA). The carrier gas was helium with the flow rate of $5 \mathrm{ml} \cdot \mathrm{min}^{-1}$. The temperature of column was kept for $3 \mathrm{~min}$ at $60^{\circ} \mathrm{C}$ then increased up to $200^{\circ} \mathrm{C}\left(7^{\circ} \mathrm{C} \cdot \mathrm{min}^{-1}\right)$. This temperature was held for $20 \mathrm{~min}$. The temperature of detector was $250^{\circ} \mathrm{C}$, and split flow was $10 \mathrm{ml} \cdot \mathrm{min}^{-1}$ (de Man, 1964; Domagała et al., 2010).

\section{Serum and blood analysis}

Serum was analysed for the concentration of total cholesterol (cat no. Liquick Cor-CHOL60 2-204), HDL-cholesterol (cat no. Cormay HDL 2-052) and triacylglycerides (cat no. Liquick Cor-TG60 2-253) (PZ Cormay S.A. Lublin, Poland). The differences between TC and HDL were used for calculations of LDL level (Friedewald et al., 1972). The concentration of tiobarbituric acid reactive substances (TBARSs) was measured with OxiTekTBARS kit (cat no. 850-287-KI01, Zeptometrix, Bufallo, NY, USA). The C-reactive proteins (CRP) were measured with a Rat CRP Elisa kit (cat no. RH 951CRP01R Biovendor, Brno, Czech Republic). Activity of glutathione reductase (GSR) was measured in the serum of rats with a kit (cat no. GR 2368 Randox Laboratories Ltd., UK). In this method, GSR catalyses the reduction of glutathione in the presence of NADPH, which is oxidized to $\mathrm{NADP}^{+}$. Activity of superoxide dismutase (SOD) was determined in erytocytes lysate with the use of a Randox kit (cat no. SD125 Randox Laboratories Ltd., UK). According to manual, xanthine and xanthine oxidase are used to generate superoxide radicals which react with 2-(4-iodophenyl-3-(4-nitrophenol)-5-phenyltetrazolium chloride to a form of a red formazan dye. Activity of HO-1 was measured accordingly to the Turcanu et al. (1998) method. $\mathrm{BaCl}_{2}(0.250$ g) was added to $0.500 \mathrm{ml}$ of serum, vortexed for $15 \mathrm{sec}$, then $0.750 \mathrm{ml}$ benzene was added. Samples were vortexed and centrifuged. The upper benzene layer was taken for measuring the absorbance at $450 \mathrm{~nm}$. Results were shown as the concentration of bilirubin.

\section{Crude lipids concentration in selected organs}

The crude fat content was determined by the Soxhlet method with a Soxtec Avanti's 2050 Auto Extraction Unit (Tecator Foss, Hillerød, Sweden), (Fortuna et al., 2003). Samples were used for measurements of crude lipids content according to the application note of the Tecator Foss (ASN 3131) with slight modification concerning drying method
(Kopeć et al., 2013). Petroleum ether was used to extract fat. Livers, kidneys and hearts were freeze-dried in lyophilizer (Christ Alpha 1-4, Gefriertrocknungsanlangen, Germany). After freezedrying, organs were weighed, grounded and used for analysis.

\section{Gene expression}

mRNA was isolated with a commercially available kit (cat no. 610.12 Invitrogen Life Technologies, Norway) and its concentration was measured by a spectrophotometer at absorbance 260 and $280 \mathrm{~nm}$. For cDNA synthesis mRNA was reverse transcribed with the use of a SuperScript ${ }^{\circledR}$ VILO cDNA Synthesis Kit (11754-050 Invitrogen Life Technologies, Norway). cDNA was subjected to real time PCR in a reaction of a mixture containing TaqMan Gene Expression Master mix and primers with fluorescent marked starters (Invitrogen, Life Technologies, Norway). The thermal profile of the PCR reaction included initial denaturation for $15 \mathrm{~min}$ at $95^{\circ} \mathrm{C}$, followed by 40 amplification cycles of denaturation for $1 \mathrm{sec}$ at $95^{\circ} \mathrm{C}$, annealing for $20 \mathrm{sec}$ at $60^{\circ} \mathrm{C}$, and elongation for $20 \mathrm{sec}$ at $72^{\circ} \mathrm{C}$. RT-PCR reaction was performed with the use of the Applied Biosystems 7900HT Fast Real-Time PCR System. The expression rates were calculated as the normalized treshold cycle $\left(\mathrm{C}_{\mathrm{T}}\right)$ difference between a control sample and a sample with the adjustment for the amplification efficiency relative to the expression level of the housekeeping gene $S p 1$.

\section{Statistical analysis}

The data was presented as mean \pm SD. Oneway, non-parametric analysis of variance (Statistica v. 8.1, StatSoft, Inc. 2007, Tulsa, OK, USA) was applied for testing the differences between experimental treatments. The Kruskal-Wallis test was used for the identification of statistically significant differences at a level of $p<0.05$.

\section{Results}

\section{Food intake, body weight gain and chosen organs weight}

Food intake of rats fed experimental diets was not significantly different among experimental groups. Experimental diets in the presence or absence of RSV did not affect body weight gain of experimental rats. There were not differences in the liver weight of rats fed the negative control (NC) diet and other experimental diets. Kidneys and heart mass was also not affected by different dietary treatments (data not showed). 
Table 2. Serum lipids, selected biochemical parameters concentration, activity of chosen antioxidant enzymes and their mRNA expression

\begin{tabular}{|c|c|c|c|c|}
\hline Parameters & $\mathrm{NC}$ & PC & $P C+$ RSV $0.05 \%$ & PC + RSV $0.1 \%$ \\
\hline \multicolumn{5}{|c|}{ Lipid profile CRP and TBARS level } \\
\hline $\mathrm{TC}, \mathrm{mmol} \cdot \mathrm{I}^{-1}$ & $2.16 \pm 0.22^{\mathrm{a}}$ & $3.69 \pm 0.44^{b}$ & $2.11 \pm 0.24^{a}$ & $2.19 \pm 0.49^{a}$ \\
\hline $\mathrm{HDL}, \mathrm{mmol} \cdot \mathrm{I}^{-1}$ & $1.47 \pm 0.18^{\mathrm{a}}$ & $1.34 \pm 0.30^{\mathrm{ac}}$ & $1.24 \pm 0.27^{\mathrm{ac}}$ & $1.16 \pm 0.09^{b}$ \\
\hline HDL/TC ratio & $0.83 \pm 0.13^{a}$ & $0.44 \pm 0.11^{b}$ & $0.59 \pm 0.15^{c}$ & $0.55 \pm 0.09^{c}$ \\
\hline $\mathrm{LDL}, \mathrm{mmol} \cdot \mathrm{I}^{-1}$ & $0.31 \pm 0.26^{b}$ & $1.72 \pm 0.44^{a}$ & $0.86 \pm 0.37^{c}$ & $1.03 \pm 0.49^{c}$ \\
\hline $\mathrm{TAG}, \mathrm{mmol} \cdot \mathrm{I}^{-1}$ & $2.34 \pm 0.52^{\mathrm{a}}$ & $2.36 \pm 0.64^{a}$ & $1.54 \pm 0.59^{b}$ & $2.15 \pm 0.48^{\mathrm{a}}$ \\
\hline $\mathrm{CRP}, \mu \mathrm{g} \mathrm{ml^{-1 }}$ & $247.6 \pm 18.8$ & $250.6 \pm 25.7$ & $242.6 \pm 16.4$ & $248.2 \pm 19.2$ \\
\hline TBARS†, nmol $\left.\cdot\right|^{-1}$ & $36.06 \pm 11.6^{\mathrm{a}}$ & $36.2 \pm 10.5^{\mathrm{a}}$ & $28.7 \pm 6.7^{\mathrm{bc}}$ & $18.9 \pm 1.6 b c$ \\
\hline \multicolumn{5}{|c|}{ Selected antioxidant enzymes activity } \\
\hline GSR, $\left.U \cdot\right|^{-1}$ & $47.3 \pm 2.36^{a}$ & $39.9 \pm 7.05^{\mathrm{ac}}$ & $37.2 \pm 12.0^{\mathrm{bc}}$ & $39.7 \pm 1.99^{a c}$ \\
\hline $\mathrm{SOD}, \mathrm{U} \cdot \mathrm{ml}^{-1 * *}$ & $122.5 \pm 50.7$ & $103.2 \pm 51.7$ & $91.9 \pm 19.8$ & $104.0 \pm 48.3$ \\
\hline $\mathrm{HO}-1, \mathrm{mmol} \cdot \mathrm{I}^{-1} \mathrm{t \dagger}$ & $1.96 \pm 0.49$ & $1.71 \pm 0.32$ & $1.60 \pm 0.52$ & $1.58 \pm 0.38$ \\
\hline \multicolumn{5}{|c|}{ Relative mRNA gene expression of selected antioxidant enzymes } \\
\hline Gsr & $1.84 \pm 0.02$ & $1.82 \pm 0.02$ & $1.86 \pm 0.02$ & $1.87 \pm 0.01$ \\
\hline Sod & $1.32 \pm 0.01$ & $1.30 \pm 0.06$ & $1.28 \pm 0.03$ & $1.29 \pm 0.01$ \\
\hline Hmox1 & $1.87 \pm 0.02$ & $1.90 \pm 0.04$ & $1.90 \pm 0.03$ & $1.90 \pm 0.03$ \\
\hline Gpx & $1.55 \pm 0.01$ & $1.49 \pm 0.06$ & $1.47 \pm 0.03$ & $1.48 \pm 0.02$ \\
\hline
\end{tabular}

* SD - standard deviation; values in column with different letters $(a, b, c)$ are significantly different, $p \leq 0.05 ;{ }^{* *}$ measured in lysate of erythrocytes; $\dagger$ expressed as the MDA equivalent; †† expressed as the amount of bilirubin mmol $\cdot \mathrm{I}^{-1}$; NC-AIN-93G diet; PC - hypercholesterolaemic diet; PC $+0.05 \%$ RSV - hypercholesterolaemic diet with addition of $0.05 \%$ RSV; PC + $0.1 \%$ RSV - hypercholesterolaemic diet with addition of $0.1 \%$ $\mathrm{RSV}$; TC - total cholesterol, TAG - triacylglycerols, CRP - C-reactive proteins, TBARS - tiobarbituric acid reactive substances, GSR - glutathione reductase, SOD - superoxide dismutase, HO-1 - haeme oxygenase 1

\section{Lipid profile, TBARs and CRP level}

The level of TC was significantly decreased in the serum of rats fed with the addition of $0.05 \%$ and $0.1 \%$ of resveratrol compared to the group fed with the PC diet. There were no differences between the concentration of TC in the serum of rats fed with the NC diet and those fed with different levels of RSV (Table 2). HDL cholesterol was significantly lower in the serum of rats fed a diet with $0.1 \%$ of RSV compared to the NC group. LDL content was significantly lower in the serum of rats fed with the $\mathrm{PC}+\mathrm{RSV} 0.05 \%$ and $\mathrm{PC}+\mathrm{RSV} 0.1 \%$ diets compared to the PC group. TAG level was significantly lower in the serum of rats fed with $0.05 \%$ of RSV in comparison to other experimental groups. The concentration of CRP in the serum of rats fed with various experimental diets did not significantly differ.

The content of TBARSs (MDA equivalents) significantly decreased in the serum of animals fed diets with different level of RSV compared to the $\mathrm{NC}$ and PC groups.

\section{Activity and mRNA expression of chosen antioxidant enzymes}

SOD and HO-1 activity was not affected by a PC diet or the addition of RSV to that diet (Table 2). Activity of GSR was significantly lower in the serum of rats fed with the diet containing $0.05 \%$ of RSV compared to the NC group. mRNA expression of Gsr, Sod, Hmoxl and Gpx was not affected by dietary treatment (Table 2).

\section{Concentration of crude lipids in liver, heart and kidneys}

After 8 weeks of the experiment the lowest content of crude lipids in the liver was determined in the group of animals fed with the diet containing $0.1 \%$ of RSV $\left(14.97 \pm 3.46 \mathrm{~g} \cdot 100 \mathrm{~g} \mathrm{DM}^{-1}\right)$ and the highest in livers of rats fed with the PC $\operatorname{diet}\left(18.88 \pm 4.55 \mathrm{~g} \cdot 100 \mathrm{~g} \mathrm{DM}^{-1}\right)$ albeit these differences were not significant (Table 3 ). The concentration of total fat in the hearts of rats was the lowest in the group fed the diet with $0.1 \%$ of RSV, and the highest in the group of animals fed with $\mathrm{NC}$ $\operatorname{diet}\left(7.11 \pm 0.64 \mathrm{~g} \cdot 100 \mathrm{~g} \mathrm{DM}^{-1}\right)$. Content of fat in hearts of rats fed with 0.05 or $0.1 \%$ of RSV was significantly lower compared to hearts of rats fed with $\mathrm{NC}$ diet. The significantly $(p<0.05)$ lowest total fat in the kidneys of animals was measured in the group fed with $0.05 \%$ and $0.1 \%$ of RSV compared to the group fed with the PC diet. There were no differences in the fat content in kidneys of animals fed with the RSV (both levels) and the NC diet.

Table 3. Concentration of crude lipids in selected organs of rats, $\%$

\begin{tabular}{llll}
\hline Treatment & Heart & Liver & Kidney \\
\hline NC & $8.44 \pm 3.50^{\mathrm{b}}$ & $13.5 \pm 3.90$ & $13.6 \pm 1.66^{\mathrm{a}}$ \\
PC & $5.94 \pm 0.24^{\mathrm{a}}$ & $18.9 \pm 4.55$ & $15.8 \pm 1.64^{\mathrm{b}}$ \\
PC + RSV 0.05\% & $5.55 \pm 0.55^{\mathrm{a}}$ & $18.4 \pm 6.07$ & $13.9 \pm 1.97^{\mathrm{a}}$ \\
PC + RSV 0.1\% & $5.34 \pm 0.53^{\mathrm{a}}$ & $14.9 \pm 3.46$ & $13.3 \pm 2.18^{\mathrm{a}}$ \\
\hline
\end{tabular}

* SD - standard deviation; values in column with different letters (a, b, c) are significantly different, $p \leq 0.05$; NC - AIN-93G diet; PC hypercholesterolaemic diet; PC+0.05\% RSV - hypercholesterolaemic dietwith addition of $0.05 \%$ RSV; PC+0.1\% RSV-hypercholesterolaemic diet with addition of $0.1 \%$ RSV 


\section{Discussion}

In this study the effects of RSV on food intake, body weight gain and organs weight of rats (data not showed) were not found. These results indicate that in terms of growth, the doses of resveratrol used in this study were tolerated by the rats. Our results correspond with data published by other authors. Aubin et al. (2008) reported also, that food intake, body weight gain, liver and heart weight of rats was not affected by resveratrol $\left(20 \mathrm{mg} \cdot \mathrm{kg}^{-1} \cdot\right.$ day $\left.^{-1}\right)$ added to a high fat diet ( $42 \%$ lipids, $36 \%$ carbohydrates and $22 \%$ protein). Juan et al. (2002) showed that the 28-day oral administration of RSV in high dose $\left(20 \mathrm{mg} \cdot \mathrm{kg}^{-1}\right.$ body weight), has no effect on the body weight gain of rats fed with a rodent commercial diet, containing $16.04 \%$ protein, $2.6 \%$ fibre, $46.74 \%$ carbohydrate, $2.95 \%$ lipids and $4.22 \%$ ash. They also did not report any effect of RSV on food intake. Tauriainen et al. (2011) found that both low and high content of RSV $\left(2 \mathrm{mg} \cdot \mathrm{kg}^{-1}\right.$ or $4 \mathrm{mg} \cdot \mathrm{kg}^{-1}$ diet, respectively) in the diet have no effect on body weight gains of mice. Albeit in some animal studies, especially with mice different models, it was shown that RSV reduces body weight gain or may affect the weight of organs (Ahn et al., 2008; Aribal et al., 2009; Kim et al., 2011; Kitada et al., 2011). Ahn et al. (2008) reported that mice fed atherogenic diet ( $1 \%$ cholesterol, $8 \%$ cocoa butter and oil) with $0.0125 \%$ RSV had lower body gain and liver weight compare to control animals. These authors did not reported intake of diets during the experiment. Kim et al. (2011) reported that male C57BL/6 mice fed with a diet containing $20 \%$ of fat $(17 \%$ lard and $3 \%$ maize oil), $1 \%$ of cholesterol and $0.4 \%$ RSV had lower body gain without affecting food intake. It can be suggested that the lowering body gain effect of RSV depend on used dose of it and animal model.

The level of TC was significantly decreased $(p<0.05)$ in the serum of rats fed with different levels of RSV compared to the serum of animals fed with the PC diet (Table 2). It has been previously reported that RSV may inhibit certain enzymes in cholesterol synthesis and mRNA gene expression involved in the lipid and sterol metabolism (Ahn et al., 2008; Kim et al., 2011; Azorín-Ortuño et al., 2012). It can be suggested that, in our study, RSV added to the PC diet could inhibit cholesterol synthesis. It could result in deficiencies of endogenous cholesterol and the one from the diet that was used for the synthesis of bile acids, hormones and the other compounds. Ahn et al. (2008) reported that the level of TC in the plasma was significantly increase in mice fed atherogenic diet (1\% cholesterol, $8 \%$ cocoa butter and oil) compared to the animals fed control diet (AIN-76). These authors have shown that addition to the atherogenic diet of the RSV $(0.0125 \%)$ significantly decreased content of TC in plasma. They reported that the expression of genes involved in cholesterol synthesis (Sqle, Fdft1) was lower in the liver of mice fed the high-fat diet supplemented with RSV and it resulted in a lower cholesterol synthesis and reduced level in the serum. Additionally, Penumathsa et al. (2008) reported that plasma cholesterol significantly decreased in rats fed with the RSV $\left(20 \mathrm{mg} \cdot \mathrm{kg}^{-1}\right)$ added to hypercholesterolaemic diet (5\% cholesterol). Results obtained in this study are similar to data published by other authors (Kim et al., 2011, Schmatz et al., 2011). In contrast, Juan et al. (2002) did not find differences in the serum cholesterol between the control group and the one that was enriched with a high dose of RSV. Furthermore, the results of experiments conducted by Aubin et al. (2008) showed no significant differences in total cholesterol levels between experimental groups.

The concentration of HDL-cholesterol was significantly lower in the serum of rats fed with $0.1 \%$ RSV compared to other experimental groups, additionally the level of TC and LDL-cholesterol was also decreased. Probably it caused the lower level of HDL (Table 2). Rats naturally have high level of HDL and addition to the diet cholesterol and its sources (e.g. butter, lard) decreases the level of HDL and elevates total and LDL-cholesterol (Pisulewski et al., 2002). It was confirmed in this study. RSV lowering TC levels, also affected the reduction of the HDL cholesterol, but the ratio of HDL/TC cholesterol significantly increased in groups of rats fed with 0.05 or $0.1 \%$ RSV compared to PC group, which was important finding of this study. Ahn et al. (2008) and Aubin et al. (2008) did not find any effect of RSV on HDL level in the plasma of rats.

LDL cholesterol concentration was significantly $(p<0.05)$ lower in the serum of rats fed with $0.05 \%$ and $0.1 \%$ of RSV compared to the serum of rats fed with the PC diet (Table 2). Hypercholesterolaemic diet significantly increases cholesterol level in blood, resulting in the risk of cardiovascular diseases. Supplementation of the diet with RSV may reverse these effects. We also found that the most effective dose in reduction of LDL was at the level of $0.05 \%$ of RSV in diet. Additionally, this dose significantly $(p<0.05 \%)$ decreased the TAG level in serum of rats compared to other experimental groups (Table 2). Kim et al. (2011) showed that TAG content was lower in the plasma of mice fed with the high-fat diet in the presence of RSV $(0.4 \%)$. 
Schmatz et al. (2011) also demonstrated that the addition of RSV to drinking water $\left(10 \mathrm{mg} \cdot \mathrm{kg}^{-1}\right.$ and 20 $\mathrm{mg} \cdot \mathrm{kg}^{-1}$ ) resulted in a significant reduction in TAG levels in diabetic rats. In contrast, Juan et al. (2002) and Aubin et al. (2008) showed that oral administration of RSV did not affect the LDL, and TAG concentration in the plasma of experimental rats.

The CRP concentration in the serum of rats was not affected by a high-fat diet or addition of RSV to this diet. Kaur et al. (2007) showed that RSV in dosedepended manner suppressed the cytokine-induced CRP expression in Hep3B cells. CRP is the acute phase plasma protein that can be used as a marker not only for inflammation but can also be used as a proatherogenic factor. It was reported that CRP promotes atherotrombosis and coagulation. The level of this protein also increases in progression in some chronic diseases (diabetes, cardiovascular events, inflammatory bowel diseases, infections) (Kaur et al., 2007; Coventry et al., 2009).

In this study it was also found that TBARSs were significantly decreased in serum of rats fed PC diet with both doses of RSV (Table 2). It has been reported previously that diets containing various level of cholesterol $(0.05 \%, 0.5 \%, 1 \%)$ and various type of fat (butter, beef tallow, soya bean oil) increases oxidative stress in rat model (Yuan et al., 1998; Yuan and Kitts, 2003; Rocha et al., 2009). It was also reported that RSV decreases concentration of various oxidative products of lipid peroxidation in rats fed high cholesterol high fat diet (Rocha et al., 2009). Probably this effect is connected with strong antioxidant activity of RSV. We did not found similar data concerning the effect of resveratrol on the TBARS concentration in the serum of rats fed diet with cholesterol in available literature.

Activities of SOD and HO-1 tended to be lower in rats fed with RSV, but in case of SOD only the dose of $0.05 \%$ of the RSV given this effect (Table $2)$. Activity of GSR was significantly $(p<0.05)$ lower in the serum of rats fed the PC diet with $0.05 \%$ of RSV compared to the NC group. We also did not find any effect in different doses of RSV on mRNA Gpx, Sod, Gsr and Ho-l expression in the liver. Diet with the addition of cholesterol and butter increases oxidative stress in the organism and probably RSV as the high activity antioxidant scavenged lipid free radicals, and activities of antioxidant enzymes were not affected. These results do not correspond with data reported by other authors and this is probably connected with a lower dose of RSV used in their studies. Rocha et al. (2009) showed higher activity of SOD, catalase or superoxide dismutase in liver of rats fed a high fat diet in presence of RSV ( $1 \mathrm{mg} \cdot \mathrm{kg}^{-1}$ body weight per day). It was also reported that RSV in human hepatoma cells (HUH7) and in rats induces the HO-1 enzyme (Wagner et al., 2011). This was not confirmed in our study.

Total fat content in the hearts and the livers of experimental rats was not affected by different dietary treatment, nevertheless it tended to be lower in groups fed with RSV $(p=0.06, p=0.07$, respectively). Significantly lower total fat content was measured in kidneys of rats fed with $0.05 \%$ or $0.1 \%$ RSV compared to the PC group and did not differ from the NC group (Table 3). These results confirmed that RSV modulates lipid metabolism not only in livers and blood, but also in other organs. Accumulation of lipids in organs and tissues increases oxidative stress which results in the production of proinflammatory cytokines and chronic inflammation. For many years inflammation has been associated with microorganism's infections, but now it is well known, that it is also involved in chronic diseases (Leiro et al., 2010; Kim et al., 2011). Presence of RSV in diet may decrease accumulation of lipids and protects from non-communicable diseases. In literature usually the concentration of TC and TAG was determined in the livers or adipose tissue in rodents treated with different diets and level of RSV (Ahn et al., 2008; Macarulla et al., 2009). Lagouge et al. (2006) showed that the $0.4 \%$ addition of RSV to a high fat diet contributed to the reduction of adipose tissue. Similar results were reported by Kim et al. (2011) and Cho et al. (2012). Albeit not all studies confirm that RSV reduces body fat (Louis et al., 2011; Tauriainen et al., 2011).

\section{Conclusions}

Results obtained in this study showed that resveratrol (RSV) has strong hypocholesterolaemic effects and may decrease lipid concentration in different organs. Activities of antioxidant enzymes and their mRNA gene expression were not affected by resveratrol RSV. Using relatively high doses of RSV $(0.05 \%$ and $0.1 \%)$ was sufficient to lowering oxidative stress without involving naturally occurring mechanisms in rats (glutathione reductase, glutathione peroxidase, superoxide dismutase, haeme oxygenase 1).

\section{Ackowlegements}

Authors are grateful to Antoni Borgiasz for his help during the animal studies. 


\section{References}

Ahn J., Cho I., Kim S., Kwon D., Ha T., 2008. Dietary resveratrol alters lipid metabolism-related gene expression of mice on an atherogenic diet. J. Hepatol. 49, 1019-1028

Aribal P., Kavas G.O., Coban U., Elhan A.H., 2009. How does resveratrol change some metabolic and circulatory parameters? A preliminary study. Adv. Clin. Exp. Med. 18, 323-328

Artaud-Wild S.M. Connor S.L., Sexton G., Connor W.E., 1993. Differences in coronary mortality can be explained by differences in cholesterol and saturated fat intakes in 40 countries but not in France and Finland. A paradox. Circulation 88, 2771-2779

Aubin M.C., Lajoie C., Clément R., Gosselin H., Calderone A., Perrault L.P., 2008. Female rats fed a high-fat diet were associated with vascular dysfunction and cardiac fibrosis in the absence of overt obesity and hyperlipidemia: therapeutic potential of resveratrol. J. Pharmacol. Exp. Ther. 325, 961-968

Azorín-Ortuño M., Yáñez-Gascón M.J., Gonzáles-Sarrías Larrosa M., Vallejo F., Pallarés F.J., Lucas R., Morales J.C., Tomás-Barberáan F.A., Garcia-Conesa M.-T., Espín J.C., 2012. Effect of long-term consumption of low doses of resveratrol on diet-induced mild hypercholesterolemic in pigs: a transcriptomic approach to disease prevention. J. Nutr. Biochem. 23, 829-837

Cho S.J., Jung U.J., Choi M.S., 2012. Differential effects of low-dose resveratrol on adiposity and hepatic steatosis in diet-induced obese mice. Brit. J. Nutr. 14, 1-10

Coventry B.J., Ashdown M.L., Quinn M.A., Markovic S.N., YatomiClarke S.L., Robinson A.P., 2009. CRP identifies homeostatic immune oscillations in cancer patients: a potential treatment targeting tool? Journal Translational Medicine 30, 102 doi: 10.1186/1479-5876-7-102

de Man J.M., 1964. Determination of fatty acid composition of milk fat by dual column temperature programmed gas liquid chromatography. J. Dairy Sci. 47, 546-547

Domagała J., Sady M., Grega T., Pustkowia H., Forkiewicz A., 2010. The influence of cheese type and fat extraction method on the content of conjugated linoleic acid. J.Food Compos. Anal. 23, 238-243

Folch J., Lees M., Sloane Stanley G.H., 1957. A simple method for the isolation and purification of total lipides from animal tissues. J. Biol. Chem. 226, 497-509

Fortuna T., Juszczak L., Sobolewska-Zielińska J., 2003. Basic of food analysis. Agric. Univ. of Krakow Press (in Polish)

Friedewald W.T., Fredrick D.S., Levy R.I., 1972. Estimation of concentration of low-density lipoprotein cholesterol in plasma, without use of preparative ultracentrifuge. Clin. Chem. 18, 499-502

Juan M.E., Gonzalez-Pons E., Munuera T., Ballester J., Rodrıguez-Gil J.E., Planas J.M., 2005. Trans-resveratrol, a natural antioxidant from grapes, increases sperm output in healthy rats. J. Nutr. 135, 757-760

Kaput J.K., 2004. Diet-disease gene interaction. Nutrition 20, 26-31

Kaur G., Rao L.V.M., Agraval A., Pendurthi R., 2007. Effect of wine phenolics on cytokine-induced C-reactive protein expression. J. Thromb. Haemost. 5, 1309-1317

Kim S., Jin Y., Choi Y., Park T., 2011. Resveratrol exerts anti-obesity effect via mechanism involving down-regulation of adipogenic and inflammation processes in mice. Biochem. Pharmacol. 81,1343-1351

Kitada M., Kume S., Imaizumi N., Koya D., 2011. Resveratrol improves oxidative stress and protects against diabetic nephropathy through normalization of Mn-SOD dysfunction in AMPK SIRT1-independent pathway. Diabetes 60, 634-643
Kopeć A., Piątkowska E., Leszczyńska T., Koronowicz A., 2013. Effect of long term administration of resveratrol on lipid concentration in selected organs and liver's histology in rats fed high fructose diet. J. Funct. Foods 5, 299-305

Lagouge M., Argmann C., Gerhart-Hines Z., et al., 2006. Resveratrol improves mitochondrial function and protects against metabolic disease by activating SIRT1 and PGC-1 alpha. Cell 127, 1109-1122

Leiro J.,Varela M., Piazzon M.C., Arranz J.A., Noya M., Lamas J., 2010. The anti-inflammatory activity of the polyphenol resveratrol may be partially related to inhibition of tumor necrosis factor-a (TNF-a) pre-mRNA splicing. Mol. Immunol. 47, $1114-1120$

Louis X.L., Thandapilly S.J., Mohankumar S.K., Yu L., Taylor C.G., Zahradka P., Netticadan T., 2011. Treatment with low-dose resveratrol reverses cardiac impairment in obese prone but not in obese resistant rats. J. Nutr. Biochem. 11, 1-7

Macarulla M.T., Alberdi G., Gómez S., Tueros I., Bald C., Rodríguez V.M., Martínez J.A., Portillo M. P., 2009. Effects of different doses of resveratrol on body fat and serum parameters in rats fed a hypercaloric diet. J. Physiol. Biochem. 65, 369-376

Penumathsa S.V., Koneru S., Samuel S.M., Maulik G., Bagchi D., Yet S.F., Menono V.P., Maulik N., 2008. Strategic targets to induce neovascularization by resveratrol in hypercholesterolemic rat myocardium: role of caveolin-1, eNOS, $\mathrm{HO}-1$ and VEGF. Free Radical. Biol. Med. 45, 1027-1034

Pisulewski P.M., Kopeć A., Cieślik E., 2002. A note on the development of rat model for cholesterol and lipoprotein metabolism a short report. Pol. J. Food Nutr. Sci. 4, 63-66

Reeves P.G., 1997. Components of the AIN-93 diets as improvements in the AIN-76A diet. J. Nutr. 127, 838-841

Rocha K.K.R., Souza G.A., Ebaid G.X., Seiva F.R.F., Cataneo A.C., Novelii E.L.B., 2009. Resveratrol toxicity: effect on risk factors for atherosclerosis and hepatic oxidative stress in standard and high-fat diet. Food Chem. Toxicol. 47, 1362-1367

Schmatz R., Perreira L.B., Stefanello N. et al., 2012. Effect of resveratrol on biomarkers of oxidative stress and on the activity of delta aminolevulinic acid dehydrates in liver and kidney of streptozotocin-induced diabetes rats. Biochimie 94, 374-383

Tauriainen E., Luostarinen M., Martonen E., Finckenberg P., Kovalainen M., Huotari A., Herzig K.H., Lecklin A., Mervaala E., 2011. Distinct effects of calorie restriction and resveratrol on dietinduced obesity and fatty liver formation. J. Nutr. Metab. doi: $10.1155 / 2011 / 525094$

Tecator Foss Application note no. ASN 3131

Wagner A.E., Boesch-Saadatmani Ch., Breckwold D., Schrander Ch., Schmelzer C., Döring F., Hashida K., Hori S., Rimbach G., 2011. Ascorbic acid partly antagonized resveratrol mediated heme oxygenase-1 but not paraoxogenase-1 induction in cultured hepatocytes-role of the redox-regulated transcription factor Nrf2. BMC Complement. Altern. Med. 11,1 doi: 10.1186/1472-6882-11-1

Yamagishi K., Iso H., Kokubo Y., Saito I., Yatsuya H., Ishihara J., Inoue M., Tsugane S., 2013. Dietary intake of saturated fatty acids and incident stroke and coronary heart disease in Japanese communities: the JPHC study. Eur. Heart J. doi: 10.1093/ eurheartj/eht043.

Yuan Y.V., Kitts D.D., 2003. Dietary (n-3) fat and cholesterol alter tissue antioxidant enzymes and susceptibility to oxidation in SHR and WKY rats. J. Nutr. 133, 679-688

Yuan Y.V., Kitts D.D., Godin D.V., 1998. Variations in dietary fat and cholesterol intakes modify antioxidant status of SHR and WKY rats. J. Nutr. 128, 1620-1630

Zawistowski J., Kopeć A., Kitts D.D., 2009. Effect of a black rice extract (Oryza sativa L. indica) on cholesterol levels and plasma lipid parameters in Wistar Kyoto rats. J. Funct. Foods 1, 50-56 